\title{
Introducción a la museografía y museología en la educación básica y media
}

VÍctor Hugo Vega ${ }^{1}$

\section{Introducción}

El trabajo que nos ocupa se ha titulado definiendo el área en el que se desarrolló, más que ilustrando su contenido. Este fue abordado con propósitos netamente educacionales, y se refiere específicamente a una serie de observaciones del comportamiento del público-visitante, interactuando en un sistema museo, esto es, intenta aportar una serie de elementos que podrían desencadenar a lo menos una reflexión y quizás una revisión de la organización de los componentes y normas museográficas tal que su optimización conduzca a facilitar la museología a todo nivel especialmente a nivel estudiantil.

\section{Fundamentos}

1. Como educadores nos interesa una estrategia que atienda la conservación del patrimonio natural y cultural que:

- Sea más formativa que correctiva.

- Involucre múltiples ámbitos de acción simultánea, en especial educacionales, profesionales e institucionales.

2. Para satisfacer tales condiciones, debe provocar una actitud de colaboración de parte de la gran masa público (con énfasis en los escolares y estudiantes en general).

3. El comportamiento del público está influido y/o determinado en una proporción significativa por la información que él posea al respecto.

4. El soporte de esta información, el canal comunicador que enlaza al investigador con el público es o son los museos.

1 Museo Escolar Experimental del Salitre, Departamento Comunal de Educación, Municipalidad de María Elena, II Región, CHILE.
Justifica este trabajo, el que al final del silogismo expuesto nos planteemos:

$¿$ Comunican efectivamente los museos al gran público? o mejor dicho ¿Es posible optimizar la comunicación museo-escolares?

\section{Estrategia}

El procedimiento general adoptado consistió en:

a) Registro de observaciones del comportamiento del público visitante interactuando en el Museo Escolar de María Elena.

b) Análisis de diversas respuestas del receptor.

c) Selección de componentes posibles de corregir o modificar (emisor, el canal, el aporte, etc.)

d) Determinación de propuestas que basada en la experimentación puedan constituir una Museografía Educacional.

El método en detalle involucra las siguientes acciones:

- Manipulación de un estímulo (p.e., rotulado).

- Observación de la respuesta. Análisis de la respuesta.

- Cuantificación estadística de la clase de respuesta.

- Cualificación por comparación de la clase de respuesta, respecto de las anteriores.

- Modificación tentativa del estímulo. Verificación de la respuesta esperada.

- Cotejo de las Observaciones en a lo menos cinco locales de museos de otros lugares (incluido el Museo de San Pedro de Atacama, durante el desarrollo del Simposio).

\section{Descripciones}

Las observaciones las realizó el autor y colaboradores sobre una muestra de casi 800 individuos de una población heterogénea, a la que no se entrevistó o solicitó datos, a objeto de no influir o distorsionar su 
comportamiento en futuras visitas; podría sostenerse que gran parte de ellos se trató de estudiantes, con un promedio de asistentes de 30 a 50 individuos.

El museo consta de un salón principal de exposición de 15 × $9 \mathrm{~m}$; se ingresa a él por grandes puertas dobles situadas simétricamente sobre el eje mayor del local; la iluminación y ventilación como la distribución de vitrinas está dispuesta igualmente al mismo eje mayor.

Dispone de 30 vitrinas dobles (de sección superior e inferior), de las cuales 13 se ubican a cada lado (apoyadas a las paredes laterales del salón) y cuatro se sitúan al fondo; también sobre el eje mayor del local existe una estructura de piedra, una gran vitrina de centro y una maqueta de excavación ubicadas en ese orden desde la puerta hacia el fondo.

Exhibía en la oportunidad la unidad "6.000 años de historia del salitre" que exponía desde material lítico, hasta elementos históricos recientes.

\section{Resultados}

\section{Lateralidad}

a) Condición de entrada: Se dispuso la serie de derecha a izquierda, con vitrinas sin numeración y se omitió la flecha que señalaba el sentido del desplazamiento esperado.

b) Proceso: (una modificación por oportunidadsemana).

- Se numeró las vitrinas (numeral $10 \mathrm{~cm}$ ).

- Se marcaron flechas direccionales en el piso.

- Se instalaron flechas direccionales en un soporte a $1 \mathrm{~m}$ de altura.

- Se obstruyó una hoja de la puerta doble de ingreso, de manera que el visitante ingresara en la dirección esperada (derecha-izquierda).

c) Respuestas registradas: En las cuatro variantes se obtuvo que aproximadamente un $80 \%$ de los visitantes, luego de una vacilación inicial, se reencaminaran en la dirección izquierda a derecha (sentido de las manecillas del reloj).

d) Inferencias y/o comentarios: Analizadas las observaciones, es dable concluir que si los sistemas educacionales invierten importantes esfuerzos en provocar en condicionamiento de lateralidad izquierda-derecha por el proceso lecto-escritor, influyendo en el proceso de percepción de secuencia temporal, debe respetarse como lógica la tendencia de leer el contenido de los museos de izquierda a derecha.

Tres de los cinco museos cotejados distribuyen sus muestras de derecha a izquierda.

\section{Rotulado}

a) Condición de entrada: Se instaló un rótulo de igual tamaño al resto de la exposición. Adelante de un objeto al azar, que transcribía "los pollitos dicen, pío, pío, pío", "si usted leyó esto, avise en la puerta".

b) Proceso: (un cambio por semana)

- Se situó en la primera vitrina de la serie.

- Luego se situó en la vitrina 15, de 30.

- Después se situó en la vitrina 30.

- Se instaló un observador cerca de la vitrina que contenía el rótulo-estímulo, con el propósito de registrar cualquier tipo de respuesta que denotara haber advertido el mensaje (una sonrisa, un comentario a su acompañante, una detención especial, etc.).

c) Respuestas registradas: En las cuatro variantes no se obtuvo registro de la percepción del rótulo intrusivo.

d) Inferencias y/o comentarios: No advertir un rótulo de casi cien existentes, podría no tener importancia estadística; pero si se observa al visitante en su desplazamiento (un estudiante colaborador describió la actitud del visitante comentando: "pasan tan imperturbables como una cámara de televisión"), podría suponerse que no perciben la existencia o indicación de los rótulos que acompañan normalmente las piezas, o que requieren de presentación o elaboración especial.

Algunas primeras reflexiones se atribuyeron al carácter de la muestra, es decir, a la condición de profanos en la materia; sin embargo, observaciones aisladas con este propósito analizando el comportamiento de asistentes y especialistas, se obtuvieron datos análogos. 


\section{Ecomuseografía}

a) Condición de entrada: Se instaló una dependencia en la cual se permitió el acceso de jóvenes estudiantes visitantes, y la posibilidad de manipular, examinar, limpiar, armar, montar y en general, trabajar con él (piezas sin valor de investigación).

b) Proceso:

- Se eligió un grupo de individuos.

- Se invitó a conocer la dependencia de trabajo.

- Se permitió su actuar libre frente al material, en la oportunidad y durante el tiempo que lo desearan.

c) Respuestas registradas: Se observó que la gran mayoría de los jóvenes sometidos a la experiencia incrementaron notoriamente su asistencia al local museo, derivando en grupos de colaboradores organizados, o en academias de educación extraescolar amparadas por el museo.

d) Inferencias y/o comentarios: El aporte en colaboración, mano de obra, armado de cerámica, montaje de vitrinas, elaboración de maquetas, etc., puede entenderse como una economía de tiempo importante para los investigadores, lo cual es a todas luces recomendable adoptar este estilo participativo en el trabajo museográfico.

\section{Otras sugerencias}

- Presentación de material en vitrinas. Se ha observado la conveniencia de exhibir el material de investigación, apareado con una maqueta, diorama, ilustración o reproducción que permita visualizar la funcionalidad o contexto original de la pieza. Para el caso en estudio se utilizaron vitrinas dobles, de secciones superior e inferior instalando en cada una de ellas, arriba el material real y abajo la escena complementaria. Esta ordenación permite reducir al mínimo los rótulos o información necesaria.

- Selección y cantidad de material. Se ha constatado una vez más, la particular atención que debe otorgarse a la selección y cantidad de material a exhibir. El cotejo realizado durante el Simposio que nos ocupó respalda esta preocupación; pudo verificarse que vitrinas conteniendo materiales similares no son observados por los visitantes (p.e., colecciones de tabletas de rapé), con todos los inconvenientes que ello implica, toda vez que la preparación de vitrinas implica tiempo y recursos no "rentables" en el caso.

- Incentivo-refuerzo. Se ha constatado el eficiente efecto sobre el comportamiento de los asistentes a museos, del incentivo (educacionalmente: refuerzo) o premio otorgado ante una actitud definida como "conveniente" para el esfuerzo conservador o difusor de los museos. La adopción como norma de otorgar certificados, constancias, insignias de cooperador, incluso folletines a los escolares, incrementa las probabilidades de que reitere comportamientos como: efectuar donaciones, colaborar al rescate de piezas, denunciar sitios de interés para la investigación, etc.

- Bodegaje. Se ha observado en la fase de cotejo del trabajo, algunos elementos deficitarios comunes a gran parte de los museos visitados; el principal es quizás la carencia de bodegas adecuadas al volumen de las colecciones guardadas en él. Se da por aceptado que los museos constituyen el resguardo a la protección especializada del patrimonio cultural, situación discutible si aceptamos el deterioro que sufren piezas importantes, por la carencia de locales convenientes para cobijar el material fuera de exposición, que constituye la mayor parte, el patrimonio de los museos.

Entrevistas a diversos responsables de museos indican que las inversiones adjudicadas a ellos casi nunca consideran una proporción del gasto, asignada al equipamiento o implementación de las bodegas, orientándose fundamentalmente a salas de exposición.

Resulta importante la adopción de alguna norma que establezca, por ejemplo, que a lo menos el $30 \%$ de los fondos de inversión asignados a museos sean destinados a implementar bodegas adecuadas al material que contendrán; esto permitiría gradualmente reemplazar las familiares y frágiles cajas de cartón, en las que se estila guardar de todo, por anaqueles y cajoneras, estuches, soportes, colgadores de textilería, etc. 


\section{Palabras finales}

La tarea del investigador culmina al comunicar sus aportes más allá de intercambio de especialista, cuando su información es masificada o difundida a través de la acción museográfica.

Ella, hemos dicho, es importante como nexo entre el especialista y el público; en la medida que la comunicación sea eficiente, fluida, expedita, mayores interacciones podrán obtenerse en lo que es interés común: conservar el patrimonio natural y cultural.
Contamos con la posibilidad de experimentar buscando mejoras en esta comunicación, mas no es simple la interpretación del comportamiento, ni menos la correlación absoluta de él, con estímulos específicos; lo que describimos no aspira sino a entregar eso, una descripción que quizás sea válida para el medio social que acoge al museo aludido; ellos no excluyen que estas observaciones sean confirmadas en otros lugares, estructurando una serie de recomendaciones que optimicen la exhibición museográfica para el público en general, pero más específico aún para el público escolar y estudiantil. 